\title{
Design Space Methodology and Its Application in Interior Permanent Magnet Motor Design
}

\author{
Fan Tao*, Li Qi**, Wen Xuhui* and Xu Longya***
}

\begin{abstract}
An innovative interpretation of the per-unit interior permanent magnet (IPM) machine model known as Design Space is presented in this paper. Based on the proposed Design Space formulation, an effective computation method to predict IPM machine performance factors, such as the current and power factor in a full range of speeds, is proposed. A systematic methodology is summarized, which translates the full speed range machine design procedure into the region determination on the so-called Design Space. The effect of dc-link voltage is also analyzed in a similar manner with the current and power factor. A series of IPM motors have been designed, and a preferred motor is selected with the help of the proposed Design Space Methodology (DSM), which has the best tradeoff between the nominal voltage and the dropped voltage condition. Experiment results show that the selected motor satisfies the machine requirements and all the design constrains, such as the current and back-EMF limitations.
\end{abstract}

Keywords: Design Space, IPM machine, Motor Design, FEA

\section{Introduction}

The usage of interior permanent magnet motors (IPM) in traction application is increasing constantly in spite of the recent uncertainty regarding the availability of the raw material used for making RE permanent magnets. The most important reason for that may be the superior performance with IPM machines, such as excellent field-weakening capability, high efficiency and the supplemented reluctance torque.

However, the unchangeable excitation of permanent magnets makes the IPM machine parameter selection a challenging job. Excellent work has been done towards to the parameter selection of SPM type machines [1]. This paper firstly covers the optimal selection of the key surface PM machine equivalent circuit parameters using a novel parameter plane approach. This parameter plane is used to show how the performance requirements constrain the allowable machine design. There is also some work looking at the optimal selection of PM machine parameters for field-weakening performance [2]-[4], and it shows that ideally the characteristic current should be equal to the rated current. Excellent work have been done regarding to

\footnotetext{
* Institute of Electrical Engineering of Chinese Academic of Science, Key Laboratory of Power Electronics Drive, Beijing, P.R.China (fantao@mail.iee.ac.cn)

** Graduate University of Chinese Academy of Science P.R.China, Be ijing, P.R.China (hustliqi@mail.iee.ac.cn)

*** The Ohio State University Columbus, OH 43210, USA

Received 07 March; Accepted 9 August
}

this topic [5]-[8] for IPM machines. Nevertheless, methods proposed in literature are more or less complex with regards to aiding the parameter selection procedure. An experienced designer is still needed to obtain appropriate key machine parameters. Some other procedures proposed previously are straight forward, but can only handle the parameter selection for a single working point. A method with the capability for parameter selection with respect to the full speed range and is compute effectively computed has hardly been seen before now.

An innovative interpretation of the per-unit IPM machine model is given in the paper, which is named as the Design Space. Based on the proposed Design Space formulation, a computation effective method to predict the IPM machine performance such as current and power factor in the fullspeed range is given. A systematic methodology is summarized, which translate the full speed range machine design procedure into the region determination on the socalled Design Space. The effect of dc-link voltage variation of the machine performance is considered to some extent.

The requirements and constrains of the IPM motor in a typical traction application are summarized firstly, which forms the boundary of the final parameter region. The Design Space Methodology (DSM) is built-up from the third section. The formulas in DSM are derived, and key concepts such as unity design space and general design space is given in this section. The effect of dc-link voltage is presented as well. 
In the fourth section, a systematic procedure is given with the help of the formulas in DSM, which is used to determine the proper sets of parameter to fulfill the requirements and constrains described in section II.

In the fifth section, a series of IPM motors have been designed, and a preferred motor is selected with the help of the proposed DSM, which has the best tradeoff between the nominal voltage and the dropped voltage condition. Experiment results show that, the selected motor satisfy the machine requirements and all the design constrains, such as the current and back-EMF limitations.

\section{Requirements and Constrains of a Typical Tracti on Application}

An IPM motor used in traction applications will face quite different requirements and constraints from those of pumps and fans. A typical curve demonstrates this as Freedom CAR target of US DOE [9] as shown in Fig.1.

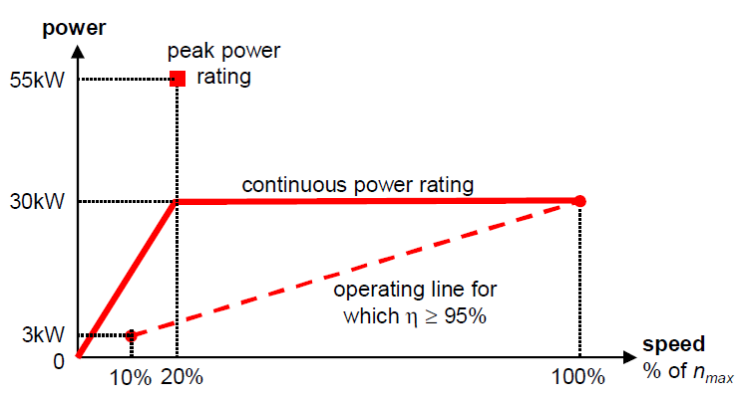

Fig. 1. FreedomCAR traction motor power requirement in a speed range

There are some key points in the curve. The first is the corner speed, which is defined as the threshold speed from where the power requirement keeps constant. The second one is the maximum speed. The ratio of the two speeds is called the constant power speed range (CPSR). A typical CPSR in a traction application is larger than 3 4. The third point is the peak power point, where peak torque is needed for a very short duration.

Dou to the great portion of the inverter cost in a traction system, the current and voltage rating of the power module in an inverter is strictly constrained. As a result, a certain current limit is imposed to the accompanying motor. A typical value of it is $2 \sim 3$ times that of the natural current at peak power.

According to previous research [10], the back-EMF at the maximum speed must be limited to a certain value in consideration of safety issues related to inverter failure.

The power versus speed requirement and all the design $\mathrm{c}$ onstrains described previously are summarized in Table I, w hich is a fixture of the US DOE target and the domestic req uirement.

Table 1. Requirements and Constrains in Traction Motor

\begin{tabular}{|l|l|l|l|}
\hline Item & Value & Item & Value \\
\hline $\begin{array}{l}\text { Continuous } \\
\text { power }\end{array}$ & $30 \mathrm{~kW}$ & $\begin{array}{l}\text { Peak } \\
\text { torque }\end{array}$ & 200Nm \\
\hline $\begin{array}{l}\text { Corner } \\
\text { speed }\end{array}$ & 2500rpm & $\begin{array}{l}\text { Nominal } \\
\text { dc-link } \\
\text { voltage }\end{array}$ & 320VDC \\
\hline $\begin{array}{l}\text { Maximum } \\
\text { speed }\end{array}$ & $7000 \mathrm{rpm}$ & $\begin{array}{l}\text { dc- } \\
\text { voltage } \\
\text { variation } \\
\text { range }\end{array}$ & 280 360VDC \\
\hline $\begin{array}{l}\text { Peak } \\
\text { power }\end{array}$ & $50 \mathrm{~kW}$ & $\begin{array}{l}\text { Current } \\
\text { limit }\end{array}$ & 270Arms \\
\hline $\begin{array}{l}\text { Rated } \\
\text { efficiency }\end{array}$ & $95 \%$ & $\begin{array}{l}\text { Line to } \\
\text { line } \\
\text { back- } \\
\text { emf } \\
\text { limit }\end{array}$ & 800Vpk@7000rpm \\
\hline
\end{tabular}

\section{Design Space Methodology}

In this section, the DSM is built-up from ground, beginning with a new interpretation of the per-unit IPM machine model. The introduction of the per-unit system brings two beneficial aspects. The first one is making the resulting formulation in a general manner. What's more important, the effect of working point switching can be seen equivalent to parameter variation.

\subsection{Per-unit IPM model}

A traditional dq-axis model of the IPM machine is listed in (1) to (4). $\xi$ is the saliency ratio. we is the angular speed measured in electrical degree. $p$ is pole number of the motor Other quantities are self-explainary.

$$
\begin{gathered}
u_{d}=\omega_{e}\left(\lambda_{m}-l_{d} i_{d}\right) \\
u_{q}=\omega \xi l_{d} i \\
u_{s}=\sqrt{u_{d}^{2}+u_{q}^{2}}=\omega_{e} \sqrt{\left(\lambda_{m}-l_{d} i_{d}\right)^{2}+\left(\xi l_{d} i_{q}\right)^{2}} \\
T=3 \frac{p}{2}\left(\lambda_{m} i_{q}+(\xi-1) l_{d} i_{d} i_{q}\right)
\end{gathered}
$$


The base value of power, voltage and speed can be chosen independently, denoted as $\mathrm{PB}, \mathrm{uB}$ and $\mathrm{nB}$. The other quantities can be expressed by them. The relationships between the base values are summarized from(5) to (8).

$$
\begin{array}{r}
T_{B}=\frac{P_{B}}{n_{B}} \\
i_{B}=\frac{P_{B}}{3 u_{B}} \\
\lambda_{B}=\frac{2 u_{B}}{p n_{B}} \\
l_{B}=\frac{6 u_{B}^{2}}{p n_{B} P_{B}}
\end{array}
$$

The per-unit IPM dq-axis model with the base value system defined previously can be derived accordingly, and listed from (9) to (12).

$$
\begin{gathered}
u_{d, p}=\omega\left(\lambda_{u}, \bar{m} l_{u}, i_{d}\right)_{t} \\
u_{q, p \bar{u}} \omega \xi_{p l} l_{d, d} i_{p} \\
u_{s, p u}=\omega_{p u} \sqrt{\left(\lambda_{m, p u}-l_{d, p u} i_{d, p u}\right)^{2}+\left(\xi l_{d, p u} i_{q, p u}\right)^{2}} \\
T_{p u}=\lambda_{, m} \dot{p}_{u}+\left(\xi_{p}-1\right) l, i_{d, p} i_{u}
\end{gathered}
$$

Comparing the per-unit model with the original one, it can be conclude that the basic format is kept unchanged, except for a few coefficients that are altered.

When the base value of power, voltage and speed are chosen as the peak power requirement, the corner speed and the nominal dc-link voltage divided by 2.34 , some meaningful results can be summarized as follow:

- Current equals 1 means the current needed to meet the power requirement equals the natural current for peak power.

- The speed equals the CPSR with respect to the corner speed.

- PM flux linkage equals 1 means the line to line backEMF at base speed equals the dc-link voltage.

- The inductance equals 1 means when the $d$-axis current equals the natural current, the line to line qaxis armature EMF at base speed equals the dc-link voltage.

\subsection{General Design Space}

The idea behind Design Space (DS) originates from the per-unit IPM model.

If the power required at certain speed and certain dc-link voltage is specified, the current needed is exclusively determined. When the dc-bus voltage is high enough to support the power, the maximum torque per ampere

(MTAP) algorithm is used to keep the current unique.

Thus, the current can be expressed by the working conditions (power, speed and voltage) and three key machine parameters, denoted in (13). The power factor can be expressed in a similar manner, such as (14).

$$
\begin{aligned}
& i_{s, p u}=D S_{P_{p u} n_{p u} u_{p u}}^{i_{s}}\left(\lambda_{m p u}, l_{d p u}, \xi\right) \\
& \cos \phi=D S_{P_{p u} f}^{p f} n_{p u}, u_{p u}\left(\lambda_{m, p u}, l_{d, p u}, \xi\right)
\end{aligned}
$$

The DS proposed is defined as the relationship between the performances (such as current and power factor), the requirements/constraints (such as power, speed and dc-link voltage) and machine parameters, denoted by DS.

The subscript of DS specifies the requirements and constraints, while the superscripts shows the type of performance the DS function calculates.

From the expression in (13) or (14), it can be concluded that, each DS is a 4-D surface from a geometric view, and there are infinite numbers of such surfaces, corresponding to the number of working points, making the performance calculation time-consuming, same as those methods in literature [5] to [8].

\subsection{Unity Design Space}

The unity design space is the expression where all the required power and speed equals 1 p.u. and the supplied dclink voltage equals 1 p.u. as well. The unity design space is denoted by $D S_{1,1,1}$.

The unity DS of current is drawn in Fig (2). As a DS is a 4-D surface, and cannot be drawn directly, a projection to the plane perpendicular to the axis of saliency ratio is used instead. From Fig (2) it can be seen that, each point in DS is a combination of machine parameters. The current for that parameter combination can be calculated from the valuelockup in the picture.

The unity DS is divided into 4 distinct regions. Region I is the non-flux weakening region; this means that if the machine parameters are designed in that region, a flux weakening algorithm is not needed to satisfy the power requirement under the supplied dc voltage. Region II and III are the flux weakening regions, but have different dependencies on the parameters. Region IV is called the invalid region. Parameter combinations in that region should be avoided. Such combinations will make the power of the motor unable to meet the power requirement at the 
specified speed.

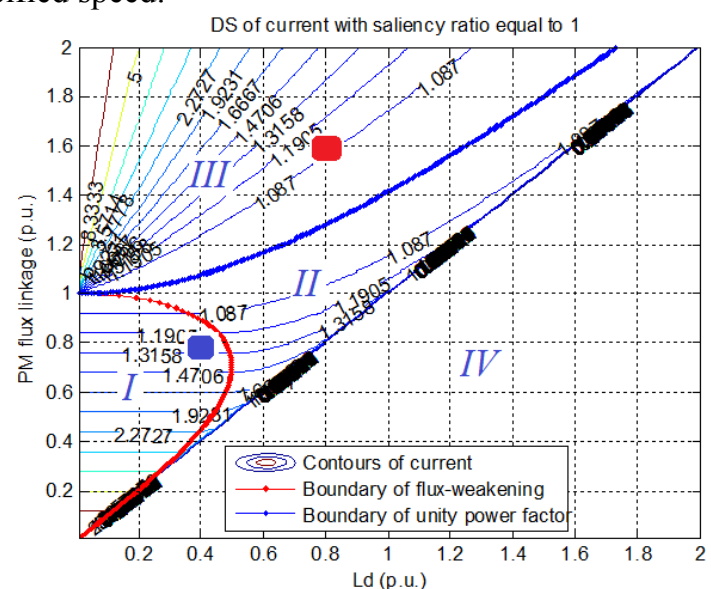

Fig. 2. Unity DS of current with a saliency ratio equal to 1

The effect of parameter variation to the motor performance can be clearly seen from the diagram of the unity DS.

The actual power of the unity DS is that the performance under other working conditions can be calculated through a similar way, with the help of (15) and (16).

In the paper, the working point is expressed by a 2-D point, denoted as $(P, n)$, meaning the power at the working point is $P$, and the speed equals to $n$; both of them are in the per-unit system. The parameter combination is expressed by a 3-D point, denoted as $\left(\lambda_{m}, p u, l_{d, p u}, \xi\right)$. The meaning of it is self-explainary.

$$
\begin{aligned}
& D S_{P_{p u}, n_{p u}, 1}^{i_{s}}\left(\lambda_{m, p u}, l_{d, p u}, \xi\right)=P_{p u} D S_{1,1,1}^{i_{s}}\left(n_{p u} \lambda_{m, p u}, n_{p u} P_{p u} l_{d, p u}, \xi\right) \\
& D S_{P p u}^{p f}, n_{p u}, 1 \\
& \left(\lambda_{m, p u}, l_{d, p u}, \xi\right)=D S_{1,1,1}^{p f}\left(n_{p u} \lambda_{m, p u}, n_{p u} P_{p u} l_{d, p u}, \xi\right)
\end{aligned}
$$

Equations (15) and (16) are the most important formulas in DSM, which make the DSM different from the method in previous works.

For example, if the selected parameter combination is $(0.4,0.8,1)$, namely the blue square in Fig. 2 , the current at the working points $(1,1)$ is about 1.25 , which is expressed by $D S_{1,1,1}^{i_{s}}(0.4,0.8,1)=1.25$.

The current at working point $(1,2)$ can be calculated as $1 \times D S_{1,1,1}^{i_{s}}(2 \times 0.4,2 \times 1 \times 0.8,1)=1.08$, which is the red square in Fig. 2.

\subsection{Current trajectory in unity DS}

This section demonstrates the power of DSM through current trajectory calculation for arbitrary power curves and arbitrary parameter combinations.

The current trajectories for parameter combination
$(0.4,0.8,1)$ to satisfy power curves in Fig. 3 are drawn in Fig4.

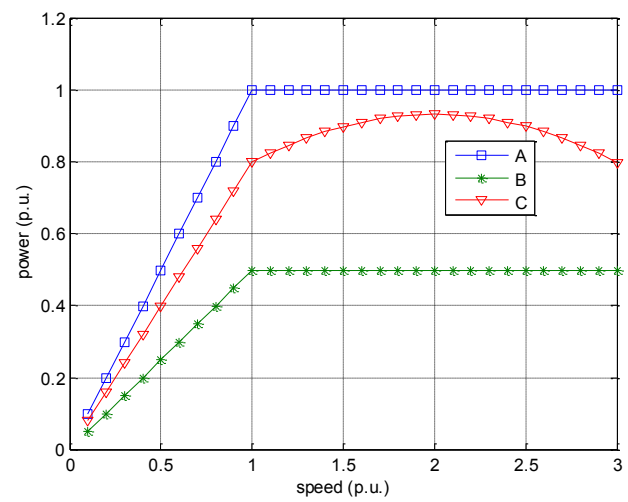

Fig. 3. Power curves in per-unit system.

If the parameter combinations are selected as $(0.4,0.8,1)$, $(0.4,0.5,1)$ and $(0.4,1.2,1)$, the parameter as well as the current trajectories corresponding to power curves A in Fig. 3 are plotted in Fig. 5.
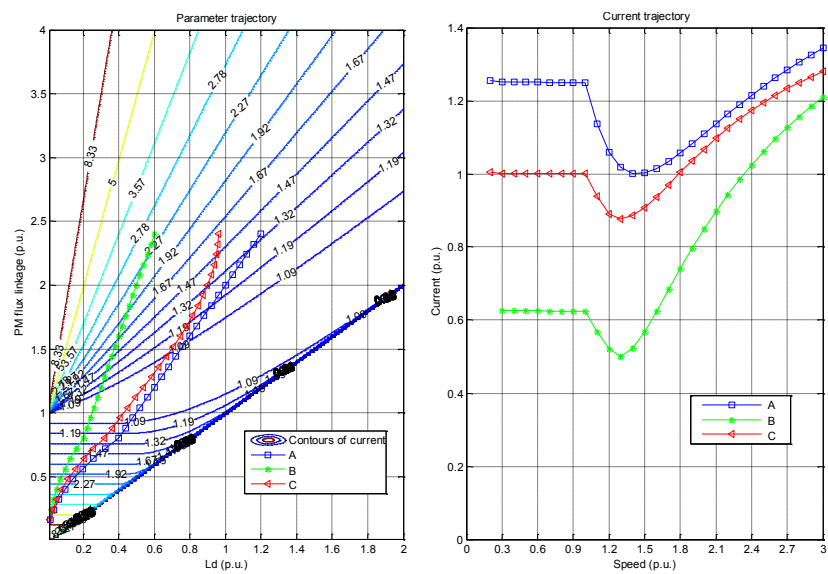

Fig. 4. Parameter trajectories and current trajectories for 3 power curves
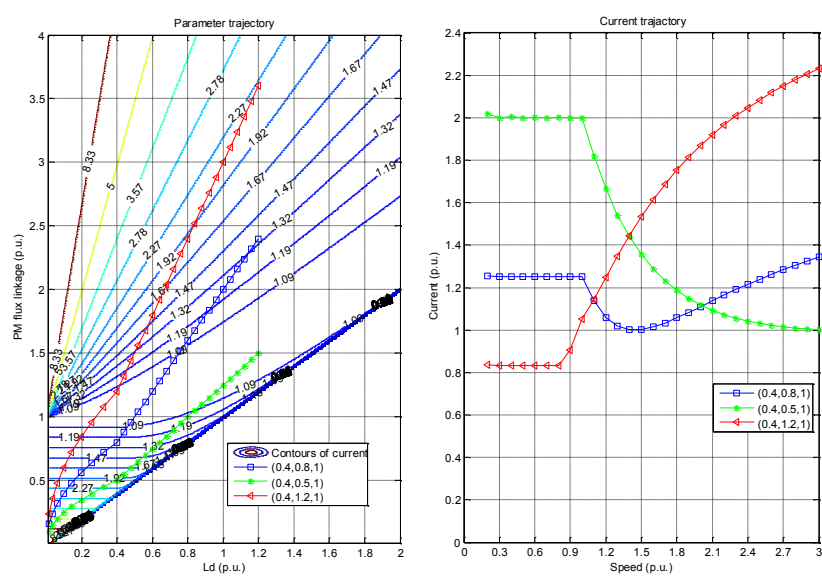

Fig. 5. Parameter trajectories and current trajectories for 3 parameter combinations 
The most common type of power curve for a traction motor is a constant torque curve below corner speed, and a constant power curve above corner speed, like the red solid line in Fig. 1. If the base value of speed is selected as the corner speed, and the base value of power is selected as the power at the corner speed. The parameter trajectory in unity DS for parameter $(\lambda 0,10, \xi 0)$ corresponding to the above mentioned power curve is expressed by (17).

It can be observed that the constant power curve is translated to a straight line in unity DS starting at point $(\lambda 0,10)$, and the constant torque curve becomes a square root function ending with the same point.

The current trajectory for that parameter combination can be easily obtained through the value of current contours in unity DS under the curve expressed by (17). No more calculation is needed except the single database behind the unity DS diagram. Caution should be taken with respect to use of a power amplifier in front of the current value obtained, such as in (15).

$$
\left\{\begin{array}{l}
\lambda_{m, p u}=\frac{\lambda_{0}}{l_{0}} l_{d p u}, \xi=\xi(n \leq 1) \\
\lambda_{m, p u}=\frac{\lambda_{0}}{\sqrt{l_{0}}} \sqrt{l_{d p u}}, \xi=\xi(n>1)
\end{array}\right.
$$

\subsection{Power factor trajectory in Unity DS}

The method for obtaining the power factor trajectory is basically the same as that used for obtaining the current. More conveniently, due to the dimension-less nature of the power factor, no more additional amplifying is needed to get the right value, unlike when getting the value for current.

The power factor trajectories for the same situation in Fig. 4 and 5 are given in Fig. 6 and 7 respectively.
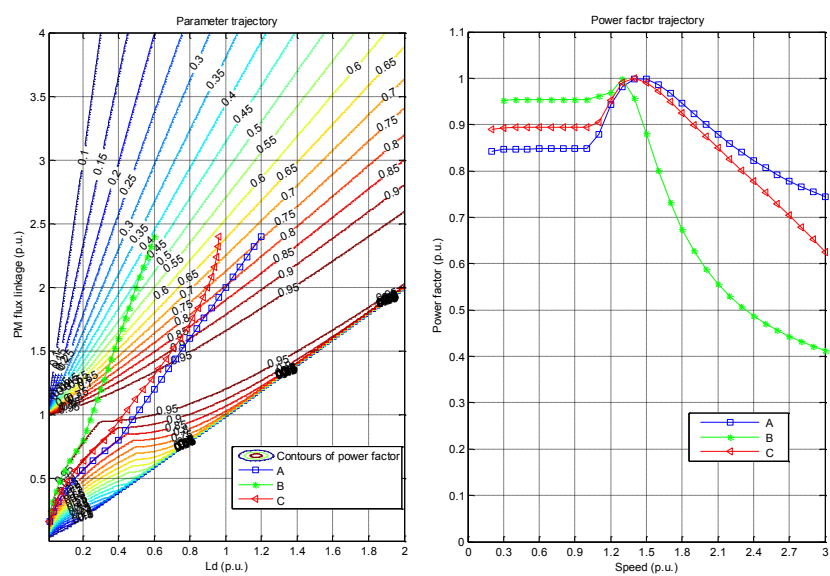

Fig. 6. Parameter trajectories and power factor trajectories
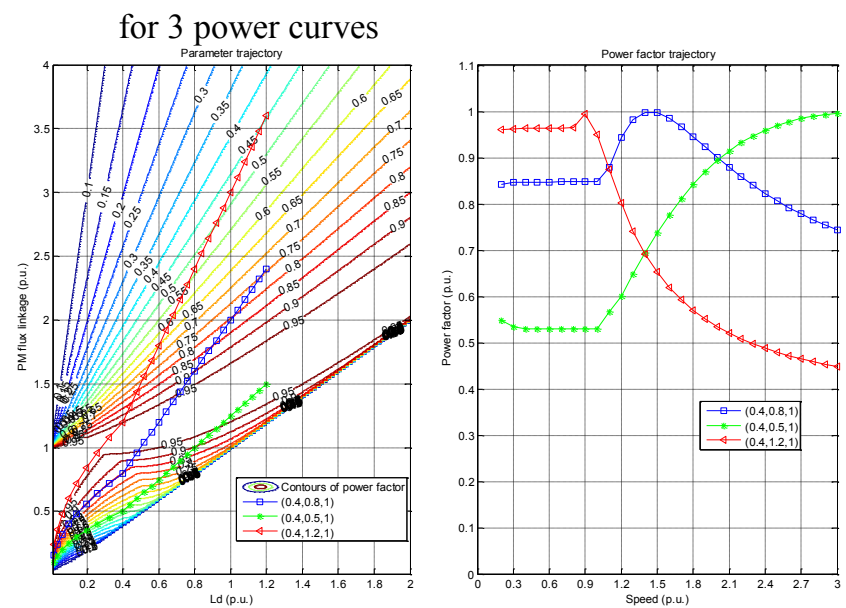

Fig. 7. Parameter trajectories and power factor trajectories for 3 parameter combinations

\subsection{Effect of dc-link voltage variation}

The supplied voltage to an IPM machine in traction application is not actually constant but has small ripple and even mild disturbances in some situations. As such, the prediction of the effect of such variation in the amplitude of the dc-link voltage on the motor performance is of great importance.

This effect can be easily handled by unity DS in a similar manner to the working point shifting, expressed in (18).

$$
\begin{gathered}
D S_{1,1, u_{p u}}^{i_{s}}\left(\lambda_{m, p u}, l_{d, p u}, \xi\right)=\frac{1}{u_{p u}} D S_{1,1,1}^{i_{s}}\left(\frac{\lambda_{m, p u}}{u_{p u}}, \frac{l_{d, p u}}{u_{p u}^{2}}, \xi\right) \\
D S_{1,1, u_{p u}}^{p f}\left(\lambda_{m, p u}, l_{d, p u}, \xi\right)=D S_{1,1,1}^{p f}\left(\frac{\lambda_{m, p u}}{u_{p u}}, \frac{l_{d, p u}}{u_{p u}^{2}}, \xi\right)
\end{gathered}
$$

With the help of (18) and (19), the effect of dc-link voltage variation to the current and power factor can be evaluated. $\pm 25 \%$ of voltage variation is assumed. Fig 8 shows the sequences of the voltage variation with the machine parameter is designed as $(0.4,0.5,1)$. It can be clearly seen that the parameter trajectory under $85 \%$ voltage goes into the invalid region on the unity DS, meaning that the power requirement can't be satisfied at high speed, which is proved in the current trajectory in the right side of Fig. 8.

\section{Parameter Region Determination using DSM}

The unity DS can handle the working condition switching and dc-link voltage variation in a straightforward and computation-effective manner as demonstrated 
in the preceding sections.

In this section, a systematic procedure using unity DS to determine the parameter region to fulfill the requirements like those in Table I is presented.
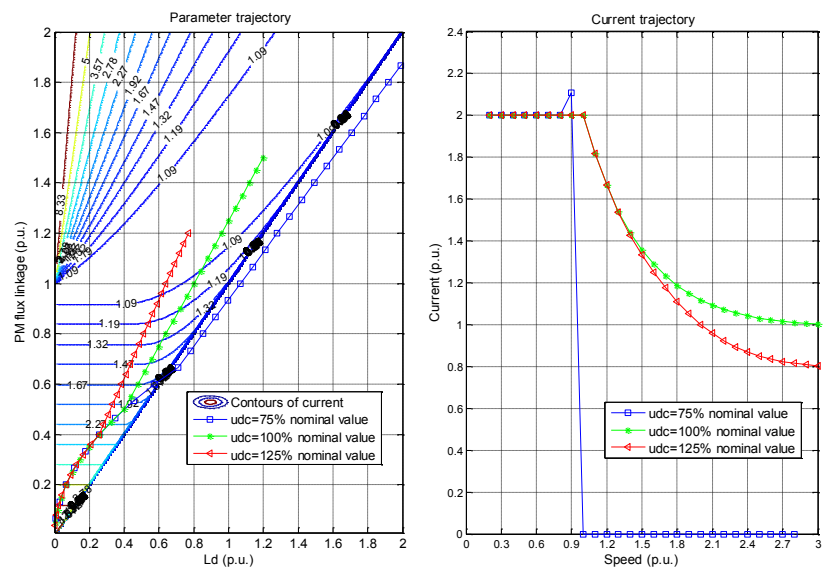

Fig. 8.Parameter trajectories and current trajectories under $\pm 25 \%$ dc-

link voltage variation with the parameter combination $(0.4$, $0.5,1)$

\subsection{Base value system selection}

The base value system is selected as those in Table II. The requirements and constrains are expressed in the resulting per-unit system and summarized in the same table.

Table 2. Base Value Selection and Requirements and Constrains in Per-Unit System

\begin{tabular}{|l|l|l|l|}
\hline Item & Base value & Item & Per-unit value \\
\hline Power & $50 \mathrm{~kW}$ & Peak power & 1 \\
\hline Speed & $2500 \mathrm{rpm}$ & $\begin{array}{l}\text { Nominal } \\
\text { voltage }\end{array}$ & 1 \\
\hline Torque & $200 \mathrm{Nm}$ & $\begin{array}{l}\text { voltage } \\
\text { variation range }\end{array}$ & $1 \pm 12.5 \%$ \\
\hline Voltage & $137 \mathrm{Vrms}$ & Current limit & 2.2 \\
\hline Current & $122 \mathrm{Arms}$ & $\begin{array}{l}\text { Line to line } \\
\text { back-emf limit }\end{array}$ & 2.5 \\
\hline Flux-linkage & $0.13 \mathrm{~Wb}$ & $\begin{array}{l}\text { Maximum } \\
\text { speed }\end{array}$ & 2.8 \\
\hline Inductance & $1.07 \mathrm{mH}$ & & \\
\hline
\end{tabular}

\subsection{Parameter selection without considering dc-voltage variation}

The solution of the following equations forms the boundary of the final parameter region to fulfill the requirements in Table II. During analysis, a saliency ratio equal to 2 is assumed.

Equation (20) represents the back-emf limit in high speed, and the other two represent the current limit for the invertor.

$$
\begin{aligned}
& \lambda_{m, p \times} 2.82 \\
& D \$_{1,1}\left(\lambda_{i m} p,{ }_{u}, l_{d},,_{t} \leq \quad 2\right. \\
& D S_{1,2 ., 1}^{i_{s}}\left(\lambda_{m, p u}, l_{d, p u}, 2\right)=D S_{1,1,1}^{i_{s}}\left(2.8 \lambda_{m, p u}, 2.8 l_{d, p u}, 2\right) \leq 2.2
\end{aligned}
$$

The final region of the parameter combination is given in Fig.9. For comparison, results when the saliency ratio equal to 1 and 3 are given in Fig.10. An increasing saliency ratio is beneficial in all aspects from the comparison.

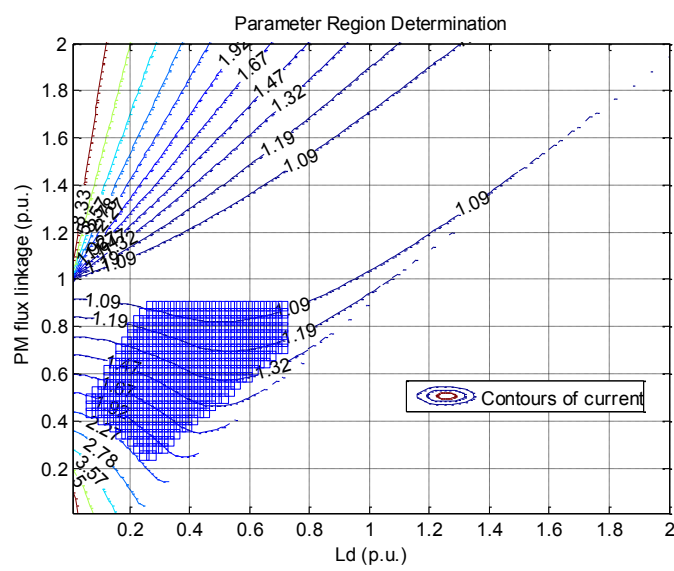

Fig. 9. Final parameter region (Saliency ratio=2)
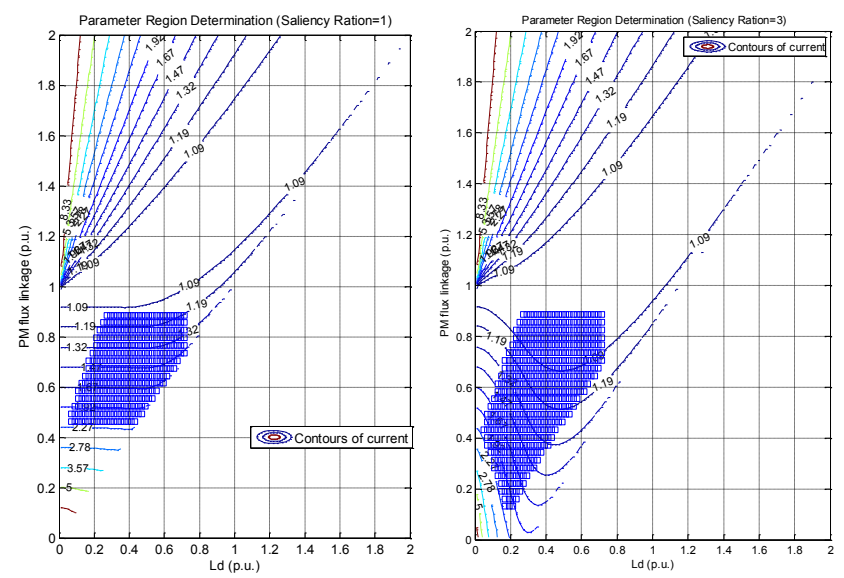

Fig. 10. Final parameter region (Saliency ratio=1, left, Saliency ratio $=3$, right)

\subsection{Parameter selection considering dc-voltage variation}

When the dc-link voltage is variable in the range as in Table II, the final parameter region is determined by (20), (23) and (24).

The blue region in Fig.9 is the appropriate parameter region when the dc-link voltage drops $12.5 \%$, and the area covered by the red square is the region corresponding to 
nominal voltage. It is clearly seen that, when the voltage drops, the reasonable region for IPM parameters shrinks to some extent.

$$
\begin{gathered}
D S_{1,1,0}^{i_{s}}\left(\lambda_{z n 7 p \tilde{x}}, l_{d p u}, 2\right) \\
=\frac{1}{0.875} D S_{1,1,1}^{i_{s}}\left(\frac{\lambda_{m, p u}}{0.875}, \frac{l_{d, p u}}{0.875^{2}}, 2\right) \leq 2.2 \\
D S_{1,2.8,0.875}^{i_{s}}\left(\lambda_{m, p u}, l_{d, p u}, 2\right) \\
=\frac{1}{0.875} D S_{1,1,1}^{i_{s}}\left(2.8 \frac{\lambda_{m, p u}}{0.875}, 2.8 \frac{l_{d, p u}}{0.875^{2}}, 2\right) \leq 2.2
\end{gathered}
$$

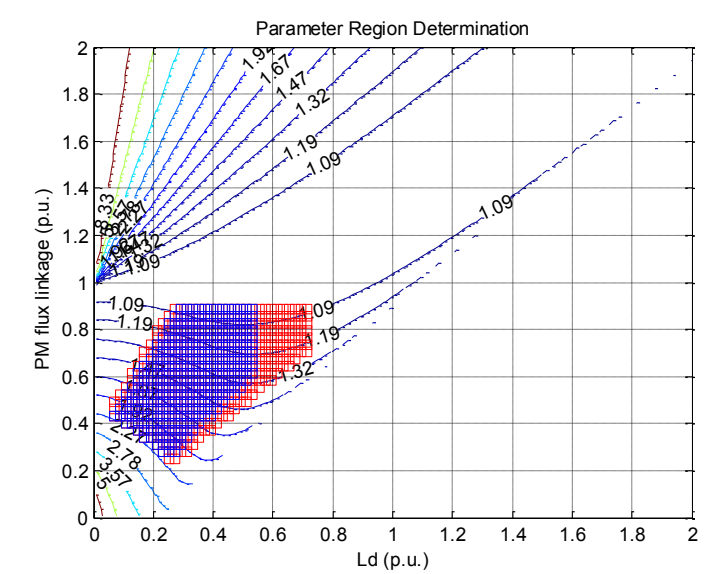

Fig. 9. Comparison of final parameter regions when dc-link voltage is considered

\section{Prototype Motor Design and Validation}

From the preceding sections, it can be seen that the DSM is both useful and computation-effective to determine the proper parameter region to fulfill the requirements and constrains for a traction motor. However, the tool is not a complete design software package. A series of formulas based on the magnetic circuit method as well as automation scripts are used to get the final design of an IPM, including the winding layout, lamination geometry, and other dimensions.

To validate the DSM proposed in this paper, a series of IPM machines are designed to fulfill the design target in Table II. The formulas and scripts mentioned in the previous paragraph are used to get a near optimal design, including winding layout and lamination geometry. All the design parameters except the number of conductors in one slot are kept same. The main parameters are summarized in Table III, and the lamination of the stator and rotor are presented in Fig. 10 .

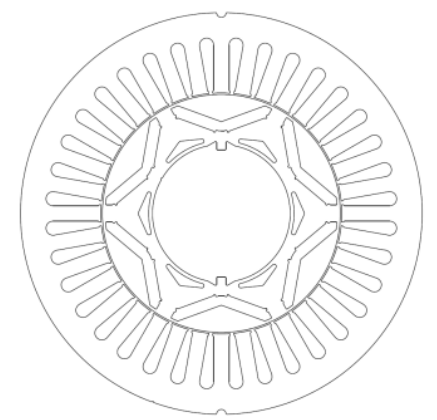

Fig. 10. The lamination of the designed IPM motor

Table 3. Main Design Parameters of Three Prototype IPM Machines

\begin{tabular}{|l|l|}
\hline Item & Value \\
\hline No. of Slots & 36 \\
\hline No. of poles & 6 \\
\hline Outer diameter of stator & $210 \mathrm{~mm}$ \\
\hline Inner diameter of stator & $126 \mathrm{~mm}$ \\
\hline Core length & $95 \mathrm{~mm}$ \\
\hline Height of airgap & $0.8 \mathrm{~mm}$ \\
\hline Winding pitch & 5 \\
\hline Magnet & NdFeB35 \\
\hline Lamination & B35A230 \\
\hline No. of conductors in a slot & $4 / 5 / 6($ MotorA/MotorB/MotorC) \\
\hline Parallel path & 1 \\
\hline
\end{tabular}

The parameters of the three IPM machines together with their per-unit value are given in Table IV. As well, the location of the three machines are plotted on the unity DS in Fig. 11 along with the pre-selected parameter region in Fig.9.

Table 4. Key Parameters of Three Prototype IPM Machines

\begin{tabular}{|l|l|l|l|}
\hline Item & Motor A & Motor B & Motor C \\
\hline Ld & 0.34 & 0.53 & 0.76 \\
\hline Saliency Ratio & 2 & 2 & 2 \\
\hline PM flux-linkage & 0.067 & 0.084 & 0.11 \\
\hline Ld (p.u.) & 0.32 & 0.50 & 0.71 \\
\hline PM flux-linkage (p.u.) & 0.52 & 0.65 & 0.85 \\
\hline
\end{tabular}

It's clearly seen that Motor C is located outside the region predicted by the DSM when the supplied voltage dropped $12.5 \%$. The current trajectories in Fig. 12 prove that Motor $\mathrm{C}$ has nearly constant current trajectory during its full speed range and the amplitude of current is the lowest among the 3 prototypes. However, when the voltage variation is considered, Motor $\mathrm{C}$ is not a good design due to its performance above 2.1 p.u. speed (corresponding to 5250rpm). Motor B is selected as the final design as it has best tradeoff between nominal voltage and low voltage conditions. 


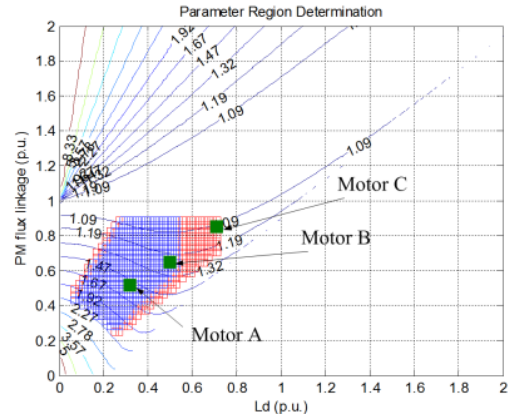

Fig. 11. Location of the three prototype machines on Unity DS
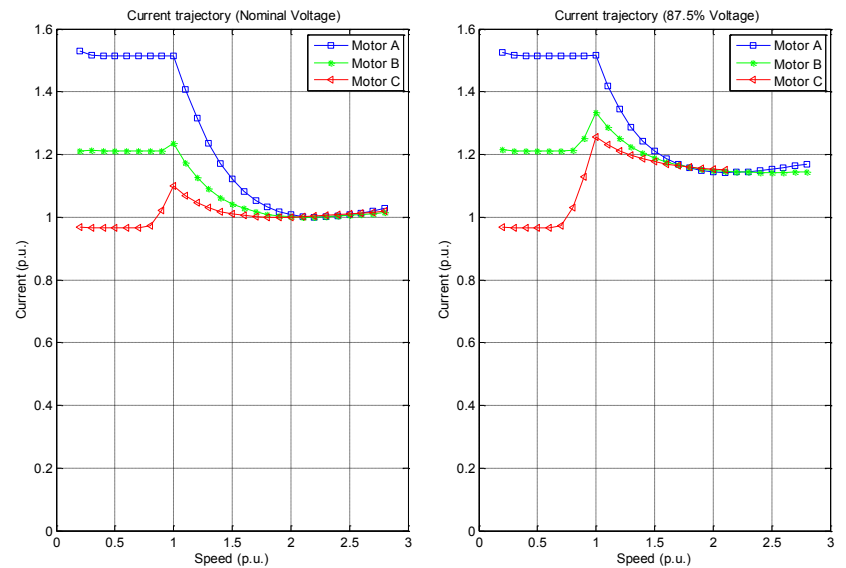

Fig. 12. Current trajectories predicted by DSM for 3 prototype machines

Curves in Fig.13 present the comparison of the current trajectories calculated by the DSM and FEA. A moderate difference is observed in the constant torque region. The main reason for that is the saturation effect during peak torque. When the torque requirement descends, a good agreement is obtained.

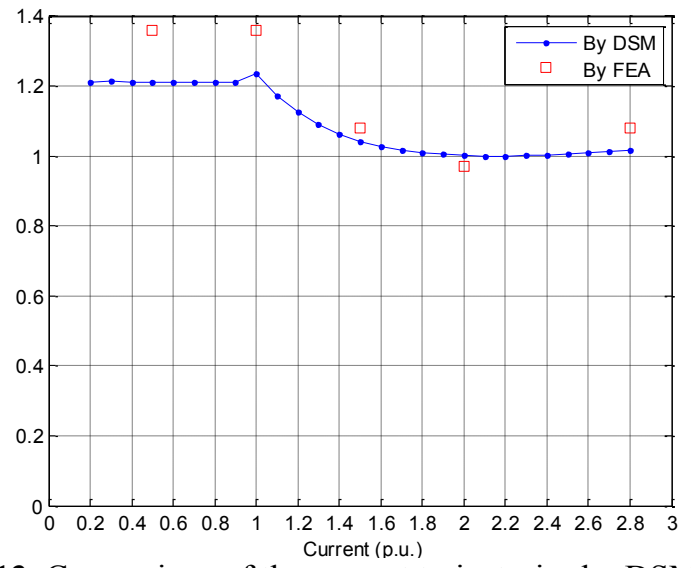

Fig. 13. Comparison of the current trajectories by DSM and FEA

Other finite element (FE) analysis results of Motor B are presented in Fig.14. A test bench of the machine has been built and the measured efficiency map under nominal voltage is drawn in Fig. 15.
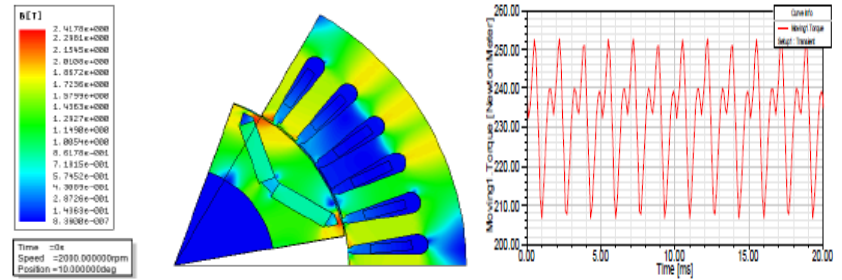

Fig. 14. Results for FEA of Motor B

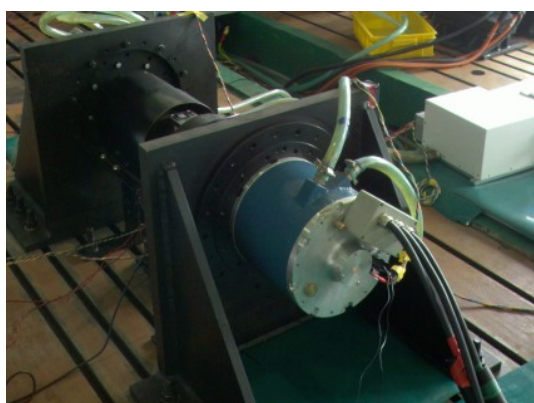

Fig. 15. Test bench of Motor B

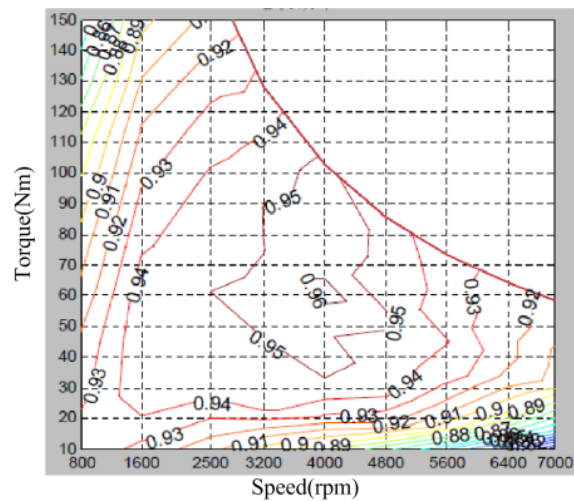

Fig. 16. Efficiency map of Motor B

\section{Conclusion}

A computation-effective tool called Design Space is proposed in the paper, which originated from an innovative interpretation of the IPM model in a per-unit system. A systematic procedure summarized as the design space methodology (DSM) is given. All important formulas of the DSM are derived thoroughly. The DSM can handle the effect of machine parameter changing, working points switching and dc-link voltage variation in a similar and straight forward manner. A series of prototypes have been designed, and a preferred design is selected with the help of the DSM. Test result validates the effectiveness of the DSM. 


\section{Acknowledgements}

This work was supported by the Innovation Program of Chinese Academy of Sciences (KGCX2-EW-324).

\section{References}

[1] A.M. EL-Refaie and T.M. Jahns, "Optimal flux weakening in surface PM machines using fractional-slot concentrated windings," IEEE Trans. on Ind. Appl., vol. 41, Issue 3, pp. 790 - 800, May/Jun. 2005.

[2] R.F. Schiferl and T.A. Lipo, "Power capability of salient pole permanent magnet synchronous motors in variable speed drive applications," IEEE Trans. on Ind. Appl., Vol. 26, Issue 1, pp. 115 - 123, Jan/Feb. 1990,

[3] S. Morimoto, M. Sanada and Y. Takeda, "Inverter-Driven Synchronous Motors for Constant Power," IEEE Industry Applications Society Magazine, pp. 18 - 24, Nov/Dec. 1996,

[4] W.L. Soong and T.J.E. Miller, "Field-Weakening Performance of the Five Classes of Brushless Synchronous AC Motor Drives," in IEE Proceedings, Electric Power Applications, vol. 141, No. 6 Nov. 1994, pp. 331-340.

[5] Fan tao, Wen Xuhui, Meng Haiying, Longya Xu, Zhao Feng and Liu Jun, "Development of the DMPM-based Electrical Variable Transmission for HEV Drive," in IEEE Proceedings of ECCE 2009, San Jose, Sept. 2009.

[6] Fan tao, Luo Jian, Wen Xuhui and Liao Xiaofeng. "Design Criteria and Procedure of Interia Permanent Magnet Machine in the Electric Vechicle Application", in IEEE Proceedings of ICEICE 2011, Wuhan, May 2011

[7] Longya Xu, Fan Tao and Wen Xuhui, "Synthesis of dimensionless indexes for IPM machine in variable speed operations", in IEEE Proceedings of ICEMS 2008, Wuhan, July 2008.

[8] Soong, W.L. Reddy, P.B. El-Refaie, A.M. Jahns, T.M. and Ertugrul, N., "Surface PM Machine Parameter Selection for Wide Field-Weakening Applications", in IEEE Proceedings of IAS 2007,Sydney, July 2007.

[9] U.S. Department of Energy, "Development of Power Electronics and Electric Motor Technology for plug-in Hybrid Electric Vehicles, Internal Combustion Engine Hybrid Electric Vehicles and Fuel Cell Vehicle Traction Drive Applications", Funding Opportunity Announcement No. DEPS26-06NT43001-00, Sept. 22, 2006: pp. 9-10.R.

[10] A. Adnanes, R. Nilssen, and R. Rad, "Power Feed-Back during Controller Failure in Inverter Fed Permanent Magnet Synchronous Motor Drives with Flux Weakening", in Proc. Of 1992 IEEE Power Elec. Spec. Conf (PESC), pp. 958-963, 1992.

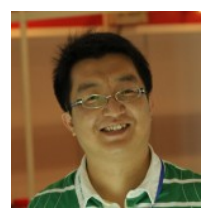

Fan Tao received his B.S degree in electric al engineering from Tsinghua University in 2004, and his M.S and PhD degrees in elect rical engineering from the Graduate Univers ity of the Chinese Academy of Sciences in 2 006 and 2009 respectively. His research interests are electri $\mathrm{c}$ machines and drive systems of electric vehicles.

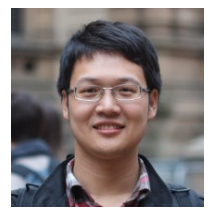

Li Qi received the B.S. degree in Electrical engineering from HuaZhong University of Science and Technology. Since September 2008, he has been studying in Institute of electrical engineering of Chinese Academic of Science. His current research interest is permanent machine design.

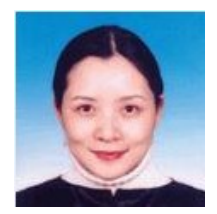

Wen Xuhui received the B.S., M.S., and $\mathrm{Ph} . \mathrm{D}$. degrees in electrical engineering from Tsinghua University, Beijing, China, in 1984, 1987, and 1993, respectively. Since 1993, she has been with the Institute of Electrical Engineering (IEE), Chinese Academy of Sciences (CAS), Beijing, China, where she became an Associate Professor in 1996 and a Professor in 1999. From 2004 to 2005, she was a Visiting Researcher with The Ohio State University. Her research fields include power electronics, motion control, and electric vehicle drives.

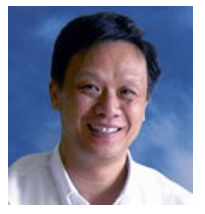

Xu Longya received the M.S. and Ph.D. degrees in electrical engineering from the University of Wisconsin, Madison, in 1986 and 1990, respectively. In 1990, he joined the Department of Electrical Engineering at Ohio State University, Columbus, where he is currently a Professor. He has served as a consultant to many industrial companies, including Raytheon Company, U.S. Wind Power Company, General Motors, Ford, and Unique Mobility Inc. His research and teaching interests include dynamic modeling and optimized design of electrical machines and power converters for variablespeed generating and drive systems, and application of advanced control theory and digital signal processors in controlling motion systems for super-high-speed operation. 